\title{
Use of proton pump inhibitors and risk of osteoporosis- related fractures
}

\author{
Laura E. Targownik MD MSHS, Lisa M. Lix PhD, Colleen J. Metge PhD, Heather J. Prior MSc, \\ Stella Leung MSc, William D. Leslie MD
}

$\infty$ See related commentary by Richards and Goltzman, page 306

\section{ABSTRACT}

Background: The use of proton pump inhibitors has been associated with an increased risk of hip fracture. We sought to further explore the relation between duration of exposure to proton pump inhibitors and osteoporosis-related fractures.

Methods: We used administrative claims data to identify patients with a fracture of the hip, vertebra or wrist between April 1996 and March 2004. Cases were each matched with 3 controls based on age, sex and comorbidities. We calculated adjusted odds ratios (OR) for the risk of hip fracture and all osteoporosis-related fractures for durations of proton pump inhibitor exposure ranging from 1 or more years to more than 7 years.

Results: We matched 15792 cases of osteoporosis-related fractures with 47289 controls. We did not detect a significant association between the overall risk of an osteoportic fracture and the use of proton pump inhibitors for durations of 6 years or less. However, exposure of 7 or more years was associated with increased risk of an osteoporosisrelated fracture (adjusted OR 1.92, 95\% confidence interval [CI] 1.16-3.18, $p=0.011$ ). We also found an increased risk of hip fracture after 5 or more years of exposure (adjusted OR $1.62,95 \% \mathrm{Cl} 1.02-2.58, p=0.04)$, with even higher risk after 7 or more years exposure (adjusted OR $4.55,95 \% \mathrm{Cl}$ 1.68-12.29, $p=0.002$ ).

Interpretation: Use of proton pump inhibitors for 7 or more years is associated with a significantly increased risk of an osteoporosis-related fracture. There is an increased risk of hip fracture after 5 or more years exposure. Further study is required to determine the clinical importance of this finding and to determine the value of osteoprotective medications for patients with long-term use of proton pump inhibitors.

Une version française de ce résumé est disponible à l'adresse www.cmaj.ca/cgi/content/full/179/4/319/DC1

CMAJ 2008;179(4):319-26

$\mathrm{O}$ steoporosis is a common condition throughout the developed world, affecting up to $16 \%$ of women and $7 \%$ of men aged 50 years and older. ${ }^{1}$ The presence of underlying osteoporosis is a major risk factor for the development of fractures of the hip, proximal femur, spinal vertebra and forearm. In 2000, the estimated number of people with fractures worldwide was 56 million, and about 9 million new osteoporotic fractures occur each year. ${ }^{2}$ In 1993/94, the number of hip fractures in Canada was $23375 .^{3}$ This number is predicted to increase to 88124 by the year 2041, with a parallel increase in the number of days in hospital (465 000 patientdays in 1993/94 to 1.8 million in 2041). ${ }^{3}$ Moreover, the casefatality rate for hip fractures can exceed $20 \%,{ }^{4}$ and all osteoporosis-related fractures can lead to substantial long-term disability and decreased quality of life. ${ }^{5}$

Many risk factors for the development of osteoporosis-related fracture have been identified, including white ethnic background, low body mass index, physical inactivity and female sex..$^{6-8}$ There are also a number of medication classes, including corticosteroids and serotonin selective reuptake inhibitors, whose use has been linked to higher rates of osteoporosis. ${ }^{9-11}$ Furthermore, any condition or drug that increases the risk of falls and injury also increases the risk of an osteoporosis-related fracture..$^{12,13}$

One medication class that may affect bone mineral metabolism is proton pump inhibitors. This class of drugs inhibits the production and intragastric secretion of hydrochloric acid, which is believed to be an important mediator of calcium absorption in the small intestine..$^{14}$ Recent studies have suggested that the use of proton pump inhibitors for 1 or more years is associated with hip fracture and other osteoporotic fractures; however, there is limited data on additional risk beyond 4 years exposure. ${ }^{15,16}$

Because proton pump inhibitors are commonly prescribed to control and prevent symptoms of chronic unrelenting conditions, it is likely that many patients will use these medications for more than 4 years. Therefore, we used an adminstrative database to examine the effects of longer durations of proton pump inhibitor use on the development of osteoporosis-related fractures.

\section{Methods}

\section{Data sources}

We performed a retrospective, matched cohort study using the Population Health Research Data Repository, which contains comprehensive health care utilization data for nearly all

From the Departments of Gastroenterology (Targownik) and General Internal Medicine (Leslie), Division of Internal Medicine, the Department of Radiology (Leslie), Division of Nuclear Medicine, the Faculty of Pharmacy (Metge), and the Manitoba Centre for Health Policy, Department of Community Health Sciences, Faculty of Medicine (Targownik, Lix, Metge, Prior, Leung), University of Manitoba, Winnipeg, Man. 
residents of Manitoba, Canada (population 1.18 million, 2006 Statistics Canada census data). ${ }^{17,18}$ Manitoba Health provides comprehensive health care coverage for residents of Manitoba and maintains computerized databases of contacts with the health care system, including demographics, date and type of service for all inpatient and outpatient contacts, and all dispensations of prescription medications. An encrypted personal identifier allows for anonymous linkage across data sets and creation of person-specific longitudinal records of health service utilization. The Population Health Research Data Repository has been extensively validated for determining the prevalence of osteoporotic fractures and the risk factors for their development. ${ }^{18,19}$ Thus, this database is well suited to explore the putative relation between the use of proton pump inhibitors and fractures of the hip, spine and wrist.

\section{Identification of cases and controls}

We defined cases as people aged 50 years and older who were seen by a physician or admitted to hospital with a diagnosis of vertebral fracture (International Classification of Diseases, 9th revision, clinical modification [ICD-9-CM] code 805), wrist fracture (ICD-9-CM code 813) or hip fracture (ICD-9-CM codes 820-821) between April 1996 and March 2004. We included patients whose hip fracture was accompanied by a physician claim for a site-specific fracture reduction or fixation. We excluded patients who had used osteoprotective medications in the year before the fracture, because these patients may have had underlying osteoporosis or a previous fracture and because their baseline risk of fracture likely exceeds the average risk in the population. Residents of longterm care facilities were also excluded because their use of prescription medication is not accurately tracked in the Manitoba Health databases. We included only patients who were continuous residents of Manitoba between 1988 and 2004 to ensure continuity of follow-up during the study period.

Each case was linked to 3 controls who had no history of hip, vertebral or wrist fractures. Controls were within 5 years of their matched case's age at the time of the fracture. They were also matched by sex, degree of comorbidity and ethnic background (Aboriginal v. non-Aboriginal). We used the Johns Hopkins aggregated diagnosis groups to determine degree of comorbidity. For each patient, we determined the number of aggregated diagnosis groups for which each patient had received a diagnosis in the year before the fracture. We grouped the degree of comorbidity into 4 categories based on the total number of aggregated diagnosis groups $(0$, $1-2,3-5, \geq 6$ ). The use of aggregated diagnosis groups to quantify comorbidity and inherent fracture risk has been previously validated for the Manitoba databases. ${ }^{18}$

\section{Determination of exposure}

We determined exposure to proton pump inhibitors using information in the Drug Program Information Network database. We separated the total exposure time for each case and control into periods of exposure to proton pump inhibitors or no exposure. A patient was considered to have been exposed to proton pump inhibitors if the ratio of standard doses dispensed to the number of days between dispensations (exclud- ing inpatient hospital days) exceeded 0.70 standard doses per day. Although we were not able to determine medications that were dispensed to inpatients, we assumed that patients continued to use proton pump inhibitors in hospital if they had taken them both before admission and after discharge.

Because the relation between use of proton pump inhibitors and osteoporotic fracture is more likely to be related to cumulative exposure than to exposure at the time of the fracture, we further grouped cases and controls based on their total duration of exposure. Patients were classified as having continuous exposure ( $>70 \%$ of their person-time before the fracture date classified as proton pump inhibitors exposure time); noncontinuous exposure ( $\geq 1$ proton pump inhibitor dispensed, but less than $70 \%$ of the patient's person-time before the fracture date classified as proton pump inhibitors exposure time); histamine-2-receptor antagonist exposure $(\geq 1$ histamine-2-receptor antagonist prescriptions dispensed, no use of proton pump inhibitors); or no exposure (no persontime before the fracture date classified as proton pump inhibitor or histamine-2-receptor antagonist exposure time).

\section{Potential confounders}

We used the Drug Program Information Network database to determine whether cases and controls were using other medications that might have affected bone metabolism or increased their risk of falls. These medications included antiandrogens, antiestrogens, bisphosphonates, vasodilatory antianginals, antihypertensives, anticoagulants, antidepressants, benzodiazepines, barbituates, antipsychotics, antiepileptics and prescription nonsteroidal anti-inflammatory drugs. We assumed that a patient was actively taking these drugs if there was at least 1 dispensation during the 120 days before the index date. Because the prescription database does not contain information about the use of over-the-counter medications, we were unable to track the use of calcium and vitamin D supplements.

We also searched inpatient and outpatient data sets to determine the presence of underlying comorbidities, including epilepsy, diabetes, ischemic heart disease, hypertension, rheumatoid arthritis, chronic obstructive pulmonary disease, prior solid organ transplant, substance use, depression, schizophrenia, dementia or home care use. We determined socioeconomic status using both area of residence (urban, rural south, rural north) and income quintiles (lowest quintiles [1-2] v. highest quintiles [3-5]; qunitiles were determined using average household income data from the 1996 Statistics Canada census). These data sets do not contain anthropomorphic measurements, such as weight or body mass index.

\section{Outcomes}

Our primary outcomes were whether the occurrence of an osteoporotic fracture was associated with the duration of continuous exposure to proton pump inhibitors. Because the Drug Program Information Network database only contains data about prescriptions dispensed since April 1995, we excluded cases and controls for whom there was insufficient data for the period of analysis (i.e., we could not assess the risk for $\geq 5$ years of proton pump inhibitor exposure for patients for 
whom the database did not contain at least 5 years of prescription data before the index date). We also determined the strength of association between continuous exposure to proton pump inhibitors and combined hip and spine fractures, and hip fractures alone.

\section{Statistical methods}

We compared differences between categorical baseline measures for cases and controls using the $\chi^{2}$ test. We considered a result statistically significant if the $p$ value was less than 0.05 . Additionally, $\chi^{2}$ tests were used to compare the use of proton pump inhibitors between cases and controls. The reference group was patients with no prior exposure to proton pump inhibitors or histamine-2-receptor antagonists. We defined conditional logistic regression models, which took case-control matching into consideration, for each of the 7 exposure intervals ( $\geq 1$ to $\geq 7$ years at 1 year intervals). We used these models to generate adjusted odds ratios (OR) and $95 \%$ confidence intervals (CI). Confounding variables included area of residence, income quintile, comorbidity (present $v$. absent), use of home care services (yes v. no) and use of medications that might have affected the risk of osteoporosis or fracture (antiandrogens, antianginals, anticoagulants, antidepressants, antiestrogens, nonsteroidal anti-inflammatory drugs, antiseizure medications, benzodiazepines, hypoglycemic agents, diuretics, systemic corticosteroids and 3-hydroxy-3-methylglutaryl-coenzyme A [HMG-CoA] reductase inhibitors [statins]). We modelled use of proton pump inhibitors as a series of dummy variables, using patients with no exposure as the reference group. We determined an odds ratio to be statistically significant if the range of the $95 \%$ confidence interval did not include 1.0 .

\section{Results}

A total of 15792 patients met our case definition between April 1996 and March 2004. These cases were matched with 47289 controls. Baseline characteristics of cases and controls, as well as all cases and controls with 5 or more years of data in the database are shown in Table 1 and Table 2. Table 3 shows the length of exposure to proton pump inhibitors for cases and controls. Overall, patients with a hip, spine or wrist fracture were significantly more likely than controls to have been diagnosed with dementia or substance abuse, and they were much more likely to have received home care services. Owing to the large sample size, there were statistically significant differences between cases and controls in many of the categories of medical history and drug use. However, the absolute difference in the rate of use between cases and controls exceeded $2 \%$ only for antiepileptics, benzodiazepines, antidepressants and nonselective nonsteroidal anti-inflammatory drugs.

The relation between length of exposure to proton pump inhibitors and any osteoporotic fracture is shown in Figure 1. There was no significant association between use of proton pump inhibitors and the development of any osteoporosisrelated fracture for patients with 1-6 years of continuous proton pump inhibitor exposure. However, after 7 years of contin-

Table 1: Baseline characteristics of 15792 cases and 47289 matched controls included in the study of the relation between the use of proton pump inhibitors and risk of osteoporosis-related fracture

\begin{tabular}{|c|c|c|c|c|}
\hline \multirow[b]{2}{*}{ Characteristic } & \multicolumn{2}{|c|}{$\begin{array}{l}\text { All patients; } \\
\text { no. }(\%) \text { of patients }\end{array}$} & \multicolumn{2}{|c|}{$\begin{array}{c}\text { Patients with } \geq 5 \text { years follow-up; } \\
\text { no. }(\%) \text { of patients }\end{array}$} \\
\hline & $\begin{array}{c}\text { Cases } \\
n=15792\end{array}$ & $\begin{array}{l}\text { Controls } \\
n=47289\end{array}$ & $\begin{array}{c}\text { Cases } \\
n=5361\end{array}$ & $\begin{array}{l}\text { Controls } \\
n=16051\end{array}$ \\
\hline \multicolumn{5}{|l|}{ Age, yr } \\
\hline $50-59$ & 2755 (17.4) & 8393 (17.7) & 1104 (20.6) & 3383 (21.1) \\
\hline $70-79$ & 4512 (28.6) & 13749 (29.1) & 1435 (26.8) & 4369 (27.2) \\
\hline$\geq 80$ & 5383 & 15807 (33.4) & 1791 (33.4) & $5268 \quad(32.8)$ \\
\hline Male & $4696 \quad(29.7)$ & $14080(29.8)$ & 1735 & 5205 (32.4) \\
\hline \multicolumn{5}{|c|}{$\begin{array}{l}\text { No. of unique aggregate } \\
\text { diagnosis groups* }\end{array}$} \\
\hline$\geq 6$ & $4649 \quad(29.4)$ & 13907 (29.4) & $1339(25.0)$ & $4008 \quad(25.0)$ \\
\hline \multicolumn{5}{|l|}{ Fracture site } \\
\hline Vertebra & 3431 (21.7) & NA & $1232(23.0)$ & NA \\
\hline Wrist & $8216 \quad(52.0)$ & NA & $2913(54.3)$ & NA \\
\hline Hip & $4145 \quad(26.2)$ & NA & 1216 & NA \\
\hline
\end{tabular}

Note: NA = not applicable.

*Johns Hopkins aggregated diagnosis groups were used to determine degree of comorbidity. For each patient, we determined the number of aggregated diagnosis groups for which each patient had received a diagnosis in the year before the fracture. 
uous exposure, there was a statistically significant association between use of proton pump inhibitors and any osteoporosisrelated fracture (adjusted OR 1.92, 95\% CI 1.16-3.18). Use of proton pump inhibitors was associated with an increased risk of hip fracture after 5 or more years of exposure (adjusted OR $1.62,95 \%$ CI 1.02-2.58) (Figure 2). The magnitude of risk for hip fracture also increased with increasing durations of exposure (adjusted OR after $\geq 6$ years 2.49, 95\% CI 1.33-4.67; adjusted OR after $\geq 7$ years $4.55,95 \%$ CI 1.68-12.29).

\section{Interpretation}

We found that use of proton pump inhibitors increased the risk of hip fracture after 5 or more years of continuous exposure. The risk of any osteoporotic fracture was increased after at least 7 years of continuous exposure to proton pump inhibitors. Patients with less than 6 years of continuous exposure were not at significantly increased risk of an osteoporosis-related fracture compared to controls, and they were not at increased risk of hip

Table 2: Comparison of baseline comorbidities and pharmacotherapies used by 15792 cases and 47289 matched controls in the study of the relation between the use of proton pump inhibitors and risk of osteoporosis-related fracture

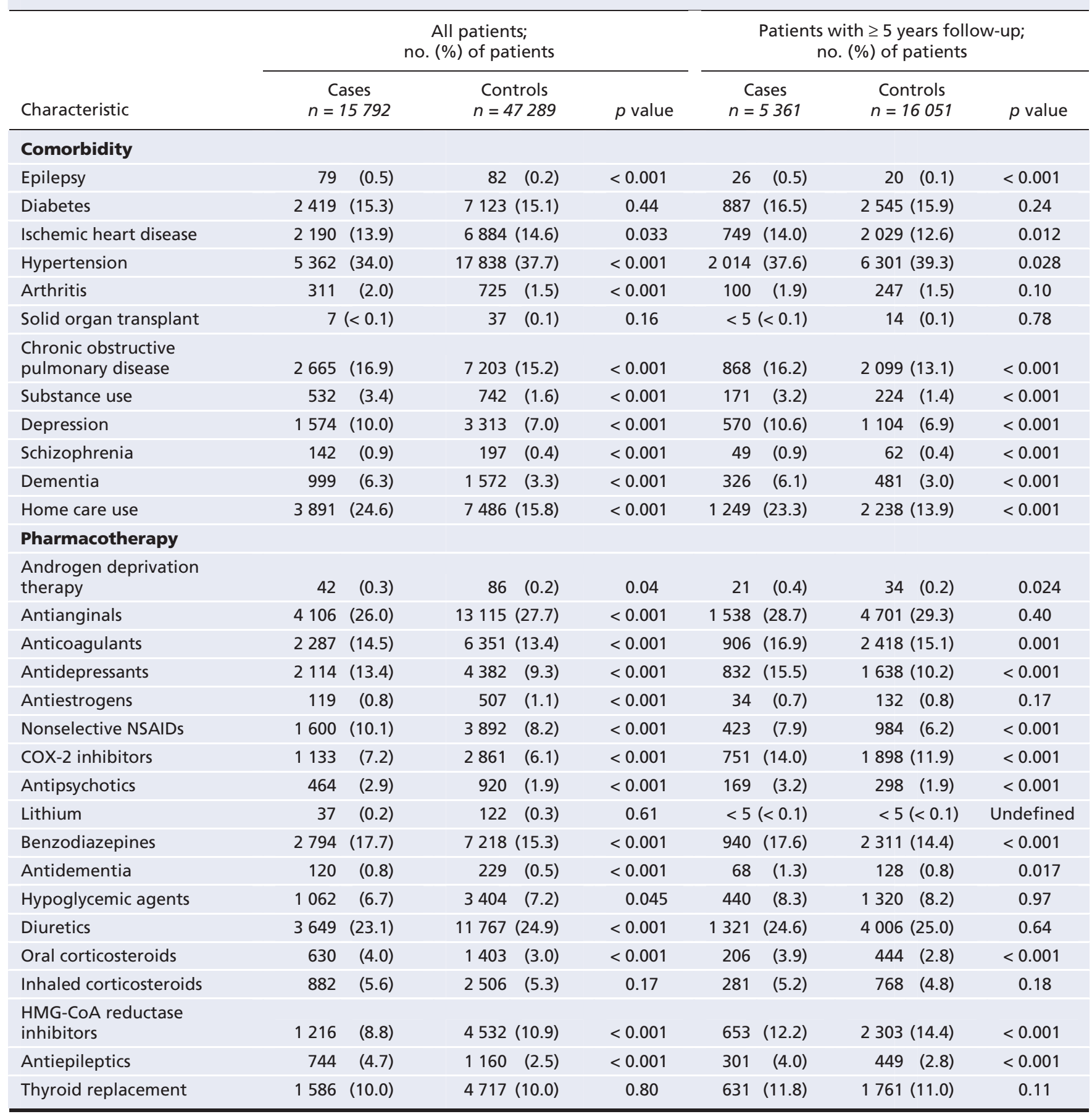

Note: COX-2 = cyclooxygenase-2, HMG-COA = 3-hydroxy-3-methylglutaryl-coenzyme A, NSAID = nonsteroidal anti-inflammatory drug. 
fracture with 4 or fewer years exposure. Although many of our odds ratios were between 1 and 2, which suggests a modest increase in the relative odds of a fracture, osteoporotic fractures are common occurrences associated with substantial morbidity and mortality, particularly with increasing age. Therefore, relatively small increases in the relative risk of a fracture may have pertinent effects on the absolute risk of events and their associated costs to the individual and society. The calculated odds ratios for exposure to proton pump inhibitors are also similar in size to those for other established osteoporotic-fracture risk factors, such as smoking, low body mass index and excessive alcohol intake. ${ }^{20}$

Our findings are consistent with those in a recent study by Yang and colleagues. ${ }^{15}$ They reported that patients with hip fractures were 1.21 times more likely than matched controls to have

Table 3: Exposure to proton pump inhibitors among 15792 cases and 47289 controls

\begin{tabular}{|c|c|c|c|}
\hline \multirow[b]{2}{*}{ Length of exposure } & \multicolumn{2}{|c|}{ No. (\%) of patients } & \multirow[b]{2}{*}{$p$ value } \\
\hline & Cases & Controls & \\
\hline$\geq 1 \mathrm{yr}$ & $n=13378$ & $n=40048$ & \\
\hline None* & $10745 \quad(80.3)$ & $32430(81.0)$ & ref \\
\hline None (with histamine-2-receptor antagonist use) $\dagger$ & $1370(10.2)$ & $3848 \quad(9.6)$ & 0.031 \\
\hline Noncontinuous $\ddagger$ & $747 \quad(5.6)$ & $2377 \quad(5.9)$ & 0.22 \\
\hline Continuous§ & $516 \quad(3.9)$ & 1393 & 0.034 \\
\hline$\geq 2$ yr & $n=11087$ & $n=33182$ & \\
\hline None & 8408 (75.8) & $25339(76.4)$ & ref \\
\hline None (with histamine-2-receptor antagonist use) & 1323 (11.9) & 3737 (11.3) & 0.06 \\
\hline Noncontinuous & $1005 \quad(9.1)$ & 3124 & 0.42 \\
\hline Continuous & $351 \quad(3.2)$ & $982 \quad(3.0)$ & 0.24 \\
\hline$\geq 3 \mathbf{y r}$ & $n=9077$ & $n=27163$ & \\
\hline None & 6534 (72.0) & $19772(72.8)$ & ref \\
\hline None (with histamine-2-receptor antagonist use) & 1178 (13.0) & 3324 (12.2) & 0.06 \\
\hline Noncontinuous & 1128 (12.4) & 3386 (12.5) & 0.83 \\
\hline Continuous & $237 \quad(2.6)$ & $681 \quad(2.5)$ & 0.50 \\
\hline$\geq 4 \mathrm{yr}$ & $n=7172$ & $n=21465$ & \\
\hline None & 4917 (68.6) & $15081(70.3)$ & ref \\
\hline None (with histamine-2-receptor antagonist use) & 997 (13.9) & $2729(12.7)$ & 0.005 \\
\hline Noncontinuous & 1095 (15.3) & $3234(15.1)$ & 0.33 \\
\hline Continuous & $163 \quad(2.3)$ & $421 \quad(2.0)$ & 0.07 \\
\hline$\geq 5$ yr & $n=5361$ & $n=16051$ & \\
\hline None & 3516 (65.6) & $11083(69.0)$ & ref \\
\hline None (with histamine-2-receptor antagonist use) & $782(14.6)$ & $2061 \quad(12.8)$ & $<0.001$ \\
\hline Noncontinuous & 949 (17.7) & $2639(16.4)$ & 0.003 \\
\hline Continuous & $114 \quad(2.1)$ & $268 \quad(1.7)$ & 0.009 \\
\hline$\geq 6 \mathrm{yr}$ & $n=3568$ & $n=10687$ & \\
\hline None & $2251 \quad(63.1)$ & $7320(68.5)$ & ref \\
\hline None (with histamine-2-receptor antagonist use) & 557 (15.6) & $1387(13.0)$ & $<0.001$ \\
\hline Noncontinuous & $698(19.6)$ & 1844 (17.3) & $<0.001$ \\
\hline Continuous & $62 \quad(1.7)$ & $136 \quad(1.3)$ & 0.011 \\
\hline$\geq 7 \mathrm{yr}$ & $n=1830$ & $n=5482$ & \\
\hline None & 1124 (61.4) & $3993(72.8)$ & ref \\
\hline None (with histamine-2-receptor antagonist use) & 291 (15.9) & $617(11.3)$ & $<0.001$ \\
\hline Noncontinuous & 383 (20.9) & $823(15.0)$ & $<0.001$ \\
\hline Continuous & $32 \quad(1.7)$ & $49 \quad(0.9)$ & $<0.001$ \\
\hline
\end{tabular}

*Patients with no person-time before the fracture date classified as proton pump inhibitor exposure time and no exposure to a histamine-2-receptor antagonist.

†Patients with $\geq 1$ prescription for a histamine-2-receptor antagonist, but no use of proton pump inhibitors.

$\ddagger$ Patients with $\geq 1$ proton pump inhibitor dispensed, but less than $70 \%$ of the patient's person-time before the fracture date classified as proton pump inhibitor exposure time.

§Patients with $>70 \%$ of their person-time before the fracture date classified as proton pump inhibitor exposure time. 
been prescribed a proton pump inhibitor for more than 1 year and 1.59 times more likely to have used a proton pump inhibitor for 4 or more years. Patients with hip fractures were also 2.65 times more likely than controls to have used proton pump inhibitors at doses more than 1.75 times the standard dose..$^{15}$ Although we did not find a significant increase in hip fractures or overall osteoporosis-related fractures among patients with less than 5 or 7 years, respectively, of continuous proton pump inhibitor exposure, our long-term results are consistent with these data.

In contrast to the study by Yang and colleagues, ${ }^{15}$ we only found an increase in the overall risk of fracture among patients who had 7 or more years of exposure to proton pump inhibitors, and an increase in the risk of hip fracture with 5 or more years of exposure. This is not surprising because bone mineralization and resorption takes place over many years, and the effect of a drug that has a subtle effect on bone mineralization may require several years of exposure before it has a measurable effect on clinical outcomes. It is possible that the finding of a significantly increased risk of fracture among patients with 1 or more years exposure by Yang and colleagues may have been because this cohort included many patients who had been using proton pump inhibitors for up to 15 years. Therefore, if a significant proportion of patients in their study cohort had extended exposure to proton pump inhibitors, those patients may have been responsible for a disproportionate share of the fracture burden. However, the study by Yang and colleagues ${ }^{15}$ does not comment on the distribution of the duration of exposure to proton pump inhibitors within the cohort with 1 or more years of exposure.

The mechanism by which extended use of proton pump inhibitors increases the risk of fracture is unknown; however, it is most likely due to the acid-inhibiting effects of proton pump inhibitors accelerating the rate of bone mineral loss. This is consistent with proton pump inhibitor exposure being more strongly associated with hip fracture than with the combined outcomes of hip, spine and wrist fractures because low bone mineral density is much more strongly associated with hip fracture than with the combined outcomes of hip, spine and wrist fractures. ${ }^{19}$ Although the precise effect of acid inhibition on bone mineral density over time is uncharacterized, there are several physiologic mechanisms by which use of proton pump inhibitors could affect bone mineral metabolism. First, the ability of the small intestine to absorb ingested calcium salts is dependent on solubility, and the solubility of calcium salts is $\mathrm{pH}$ dependent. ${ }^{21} \mathrm{Cal}-$ cium carbonate, which is the most common calcium salt found in dietary supplements, is relatively insoluble at high $\mathrm{pH}$ levels, which could potentially hinder its absorption. ${ }^{22}$ Conversely, in vitro, proton pump inhibitors inhibit bone resorption, and in vivo, proton pump inhibitors decrease urinary excretion of calcium, likely because of inhibition of vacuolar $\mathrm{H}^{+}$/ATPases found on osteoclast cell membranes. ${ }^{23}$ Therefore, further research is required to determine the precise effect of long-term use of proton pump inhibitors on bone mineral metabolism.

Our study suggests that the risk of osteoporosis-related fracture increases with the duration of exposure to proton pump inhibitors. This has specific implications for patients with longterm exposure. Because many of the common indications for proton pump inhibitor therapy are not self-limiting, ${ }^{24}$ a substantial portion of proton pump inhibitor use is of indefinite duration. Furthermore, use has been increasing in recent years, likely because of a number of factors, including increasing affordabil-

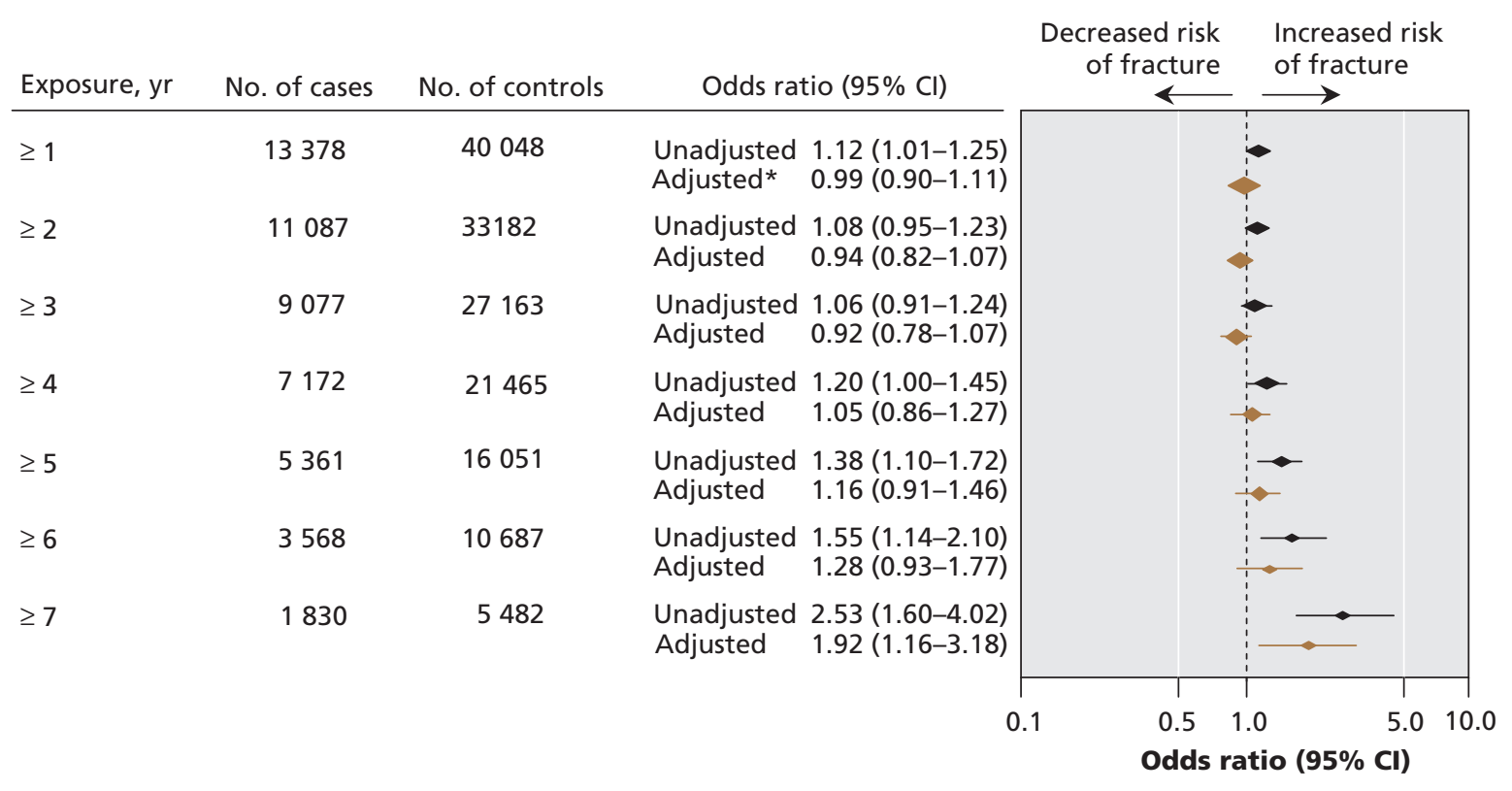

Figure 1: Association between continuous exposure to proton pump inhibitors and osteoporosis-related fractures (hip, vertebra or wrist). *Adjusted for income, region of residence, diagnoses (short- or long-term diabetes, epilepsy, ischemic heart disease, myocardial infarction, hypertension, arthritis, solid organ transplant, chronic obstructive pulmonary disease, substance use, depression, schizophrenia, dementia), home care use and multiple medications. The reference group was patients with no exposure to proton pump inhibitors or histamine-2-receptor antagonists. Note: $\mathrm{Cl}=$ confidence interval. 
ity with the emergence of generic and over-the-counter formulations, and an increasing reluctance to give cyclooxygenase- 2 inhibitors as a gastroprotective strategy for people taking nonsteroidal anti-inflammatory drugs. ${ }^{25}$ These factors may promote the long-term use of proton pump inhibitors, leaving patients at increased risk of osteoporosis-related fractures. Conversely, there is evidence that these medications are frequently given to patients with no obvious indication, ${ }^{26,27}$ and other studies have suggested that many long-term proton pump inhibitor users can be stepped-down to less intensive therapies without recurrence of symptoms. ${ }^{28,29}$ Because evidence also suggests that use of pro- ton pump inhibitors may be associated with an increased risk of enteric infections such as Clostridium difficile and community acquired pneumonia, ${ }^{30,31}$ clinicians must be increasingly vigilant in ensuring that proton pump inhibitors are used sparingly and only when absolutely indicated. However, there will remain a subset of patients for whom continuation of long-term therapy is necessary because of an underlying high-risk of gastrointestinal bleeding, recalcitrant symptoms or complications of gastroesophageal reflux disease, including peptic strictures and erosive esophagitis. Further study is required to determine whether there are pharmacologic strategies, including the use of calcium
A

\begin{tabular}{|c|c|c|c|c|}
\hline \multirow{2}{*}{$\begin{array}{l}\text { Exposure, yr } \\
\geq 1\end{array}$} & \multirow{2}{*}{$\frac{\text { No. of cases }}{6358}$} & \multirow{2}{*}{$\frac{\text { No. of controls }}{19008}$} & \multicolumn{2}{|c|}{ Odds ratio $(95 \% \mathrm{Cl})$} \\
\hline & & & $\begin{array}{l}\text { Unadjusted } \\
\text { Adjusted* }\end{array}$ & $\begin{array}{l}1.22(1.06-1.41) \\
1.03(0.88-1.20)\end{array}$ \\
\hline$\geq 2$ & 5227 & 15621 & $\begin{array}{l}\text { Unadjusted } \\
\text { Adjusted }\end{array}$ & $\begin{array}{l}1.17(0.99-1.39) \\
0.98(0.81-1.18)\end{array}$ \\
\hline$\geq 3$ & 4261 & 12732 & $\begin{array}{l}\text { Unadjusted } \\
\text { Adjusted }\end{array}$ & $\begin{array}{l}1.12(0.91-1.38) \\
0.93(0.74-1.17)\end{array}$ \\
\hline$\geq 4$ & 3319 & 9920 & $\begin{array}{l}\text { Unadjusted } \\
\text { Adjusted }\end{array}$ & $\begin{array}{l}1.24(0.96-1.61) \\
1.07(0.80-1.40)\end{array}$ \\
\hline$\geq 5$ & 2448 & 7317 & $\begin{array}{l}\text { Unadjusted } \\
\text { Adjusted }\end{array}$ & $\begin{array}{l}1.57(1.16-2.13) \\
1.31(0.94-1.82)\end{array}$ \\
\hline$\geq 6$ & 1612 & 4823 & $\begin{array}{l}\text { Unadjusted } \\
\text { Adjusted }\end{array}$ & $\begin{array}{l}1.70(1.12-2.57) \\
1.41(0.90-2.22)\end{array}$ \\
\hline$\geq 7$ & 832 & 2490 & $\begin{array}{l}\text { Unadjusted } \\
\text { Adjusted }\end{array}$ & $\begin{array}{l}2.95(1.58-5.51) \\
2.47(1.20-5.05)\end{array}$ \\
\hline
\end{tabular}

B

\begin{tabular}{lcc} 
Exposure, yr & No. of cases & No. of cont \\
\hline$\geq 1$ & 3448 & 10294 \\
$\geq 2$ & 2787 & 8316 \\
$\geq 3$ & 2228 & 6645 \\
$\geq 4$ & 1701 & 5076 \\
$\geq 5$ & 1216 & 3629 \\
$\geq 6$ & 793 & 2370 \\
$\geq 7$ & 390 & 1165
\end{tabular}

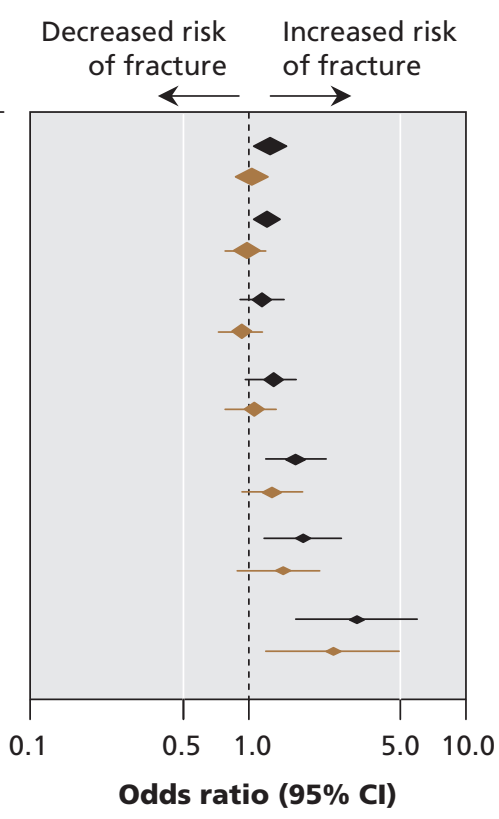

Decreased risk Increased risk

Odds ratio $(95 \% \mathrm{Cl})$

Unadjusted $1.29(1.06-1.57)$

Adjusted* $1.09(0.88-1.34)$

Unadjusted $1.20(0.94-1.53)$ Adjusted 1.01 (0.77-1.32)

Unadjusted $1.11(0.83-1.49)$ Adjusted 0.97 (0.70-1.34)

Unadjusted 1.49 (1.05-2.11) Adjusted 1.43 (0.97-2.11)

Unadjusted 1.72 (1.14-2.61) Adjusted $1.62(1.02-2.59)$

Unadjusted 2.13 (1.22-3.72) Adjusted 2.49 (1.33-4.67) Unadjusted 3.73 (1.63-8.55) Adjusted 4.55 (1.68-12.29) of fracture of fracture

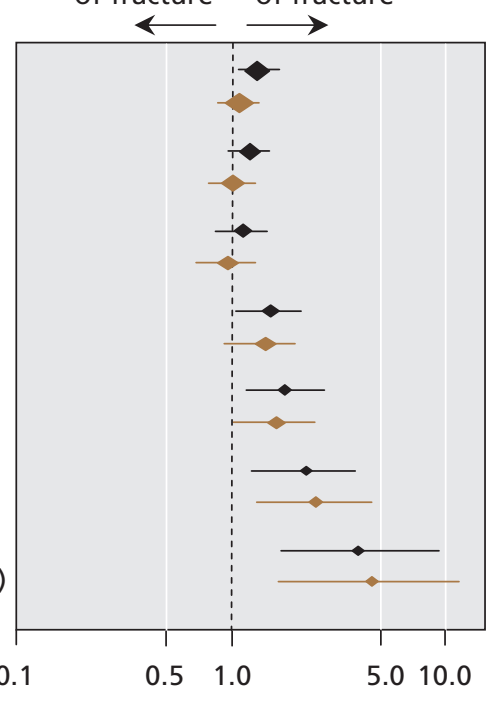

Odds ratio $(95 \% \mathrm{Cl})$

Figure 2: Relation between continuous exposure to proton pump inhibitors and (A) hip and vertebral fractures and (B) hip fractures. *Adjusted for factors listed in Figure 1. Note: $\mathrm{Cl}=$ confidence interval. 
supplementation, bisphosphonates or estrogen analogues, that can mitigate the risk of fracture..$^{32,33,34}$

Our study has some limitations that deserve further discussion. First, owing to the lack of anthropomorphic data and information about the use of over-the-counter calcium supplements, vitamin D supplements, tobacco and alcohol in our data set, we were unable to control for the possible confounding effects of these factors. We were also unable to determine whether increased fracture risk from proton pump inhibitors is related to reduced bone density or increased risk for falls; however, to our knowledge, there is no evidence that proton pump inhibitors increase falls. Second, as with any observational study, there may be unrecognized differences between cases and controls that can confound the results. Finally, fractures that do not lead to a physician interaction (which includes many vertebral fractures) cannot be identified. However, given the comprehensiveness of the Population Health Research Data Repository and its previous use for determining risk factors for osteoporotic fractures, we are confident that it is unlikely that these limitations had a profound effect on our results.

In conclusion, we detected an association between long-term ( $\geq 7$ years) exposure to proton pump inhibitors and osteoporosisrelated fractures. We also found an association between hip fractures and 5 or more years exposure to proton pump inhibitors. However, short-term use did not appear to increase fracture risk. Further study is required to examine the effect of acid inhibition on calcium absorption and bone mineral metabolism, specifically to determine the effect of acid inhibition on bone mineral density over time. As well, further research is needed to examine the role of osteoprotective medications for patients who require longterm proton pump inhibitor therapy. Lastly, as with any medication, we recommend that proton pump inhibitors be used only in clinical situations where they are necessary and in which they have been proven to be efficacious.

\section{This article has been peer reviewed.}

Competing interests: None declared for Lisa Lix, Colleen Metge, Heather Prior or Stella Leung. Laura Targownik has received funds for investigatorinitiated research from Janssen-Ortho Canada, and from Astra-Zeneca Canada, and has served on the advisory board for Janssen-Ortho Canada. She has also served on the advisory board for the Canadian Agency for Drugs and Technology in Healthcare for developing best practices guidelines for use of proton pump inhibitors in Canada.

William Leslie has received speaker's fees and research support from Merck Frosst Canada, honoraria and unrestricted educational grants from Sanofi-Aventis, Procter and Gamble Pharmaceuticals Canada, Amgen Pharmaceuticals and Genzyme Canada.

Contributors: All of the authors participated in the conception and study design, the acquisition of data, analysis and interpretation of data, and in the writing and revision of the manuscript for important intellectual content. All of the authors approved the final version submitted for publication.

Funding: This research was funded by an operating grant from the Canadian Institutes of Health Research.

\section{REFERENCES}

1. Tenenhouse A, Joseph L, Kreiger N, et al. Estimation of the prevalence of low bone density in Canadian women and men using a population-specific DXA reference standard: the Canadian Multicentre Osteoporosis Study (CaMos). Osteoporos Int 2000;11:897-904.

2. Johnell O, Kanis JA. An estimate of the worldwide prevalence and disability associated with osteoporotic fractures. Osteoporos Int 2006;17:1726-33.
3. Papadimitropoulos EA, Coyte PC, Josse RG, et al. Current and projected rates of hip fracture in Canada. CMAJ 1997;157:1357-63.

4. Hannan EL, Magaziner J, Wang JJ, et al. Mortality and locomotion 6 months after hospitalization for hip fracture: risk factors and risk-adjusted hospital outcomes. JAMA 2001;285:2736-42.

5. Adachi JD, Loannidis G, Berger C, et al. The influence of osteoporotic fractures on health-related quality of life in community-dwelling men and women across Canada. Osteoporos Int 2001;12:903-8.

6. Cummings SR, Nevitt MC, Browner WS, et al. Risk factors for hip fracture in white women. Study of Osteoporotic Fractures Research Group. $N$ Engl J Med 1995;332:767-73.

7. Ensrud KE, Cauley J, Lipschutz R, et al. Weight change and fractures in older women. Study of Osteoporotic Fractures Research Group. Arch Intern Med 1997;157:857-63.

8. Gregg EW, Cauley JA, Seeley DG, et al. Physical activity and osteoporotic fracture risk in older women. Study of Osteoporotic Fractures Research Group. Ann Intern Med 1998;129:81-8.

9. Van Staa TP, Leufkens HG, Abenhaim L, et al. Use of oral corticosteroids and risk of fractures. J Bone Miner Res 2000;15:993-1000.

10. Richards JB, Papaioannou A, Adachi JD, et al. Effect of selective serotonin reuptake inhibitors on the risk of fracture. Arch Intern Med 2007;167:188-94.

11. Haney EM, Chan BK, Diem SJ, et al. Association of low bone mineral density with selective serotonin reuptake inhibitor use by older men. Arch Intern Med 2007; $167: 1246-51$

12. Nevitt MC, Cummings SR. Type of fall and risk of hip and wrist fractures: the study of osteoporotic fractures. The Study of Osteoporotic Fractures Research Group. J Am Geriatr Soc 1993;41:1226-34

13. Cawthon PM, Harrison SL, Barrett-Connor E, et al. Alcohol intake and its relationship with bone mineral density, falls, and fracture risk in older men. $J$ Am Geriatr Soc 2006;54:1649-57.

14. Bo-Linn GW, Davis GR, Buddrus DJ, et al. An evaluation of the importance of gastric acid secretion in the absorption of dietary calcium. J Clin Invest 1984;73:640-7.

15. Yang YX, Lewis JD, Epstein S, et al. Long-term proton pump inhibitor therapy and risk of hip fracture. JAMA 2006;296:2947-53.

16. Vestergaard P, Rejnmark L, Mosekilde L. Proton pump inhibitors, histamine H2 receptor antagonists, and other antacid medications and the risk of fracture. Calcif Tissue Int 2006;79:76-83.

17. Roos NP. Establishing a population data-based policy unit. Med Care 1999;37: JS15-26.

18. Leslie WD, Anderson WA, Metge CJ, et al. Clinical risk factors for fracture in postmenopausal Canadian women: a population-based prevalence study. Bone 2007;40:991-6.

19. Leslie WD, Tsang JF, Caetano PA, et al. Effectiveness of bone density measurement for predicting osteoporotic fractures in clinical practice. J Clin Endocrinol Metab 2007;92:77-81.

20. Kanis JA, Borgstrom F, De Laet C, et al. Assessment of fracture risk. Osteoporos Int 2005; 16:581-9.

21. Ivanovich $\mathrm{P}$, Fellows $\mathrm{H}$, Rich $\mathrm{C}$. The absorption of calcium carbonate. Ann Intern Med 1967;66:917-23

22. Sheikh MS, Santa Ana CA, Nicar MJ, et al. Gastrointestinal absorption of calcium from milk and calcium salts. N Engl J Med 1987;317:532-6.

23. Mizunashi K, Furukawa Y, Katano K, et al. Effect of omeprazole, an inhibitor of $\mathrm{H}+, \mathrm{K}(+)-\mathrm{ATPase}$, on bone resorption in humans. Calcif Tissue Int 1993;53:21-5.

24. Wilcox CM, Allison J, Benzuly K, et al. Consensus development conference on the use of nonsteroidal anti-inflammatory agents, including cyclooxygenase- 2 enzyme inhibitors and aspirin. Clin Gastroenterol Hepatol 2006;4:1082-9.

25. Sun SX, Lee KY, Bertram CT, et al. Withdrawal of COX-2 selective inhibitors rofecoxib and valdecoxib: impact on NSAID and gastroprotective drug prescribing and utilization. Curr Med Res Opin 2007;23:1859-66.

26. Jacobson BC, Ferris TG, Shea TL, et al. Who is using chronic acid suppression therapy and why? Am J Gastroenterol 2003;98:51-8.

27. Pillans PI, Kubler PA, Radford JM, et al. Concordance between use of proton pump inhibitors and prescribing guidelines. Med J Aust 2000;172:16-8.

28. Inadomi JM, Jamal R, Murata GH, et al. Step-down management of gastroesophageal reflux disease. Gastroenterology 2001;121:1095-100.

29. Bjornsson E, Abrahamsson H, Simren M, et al. Discontinuation of proton pump inhibitors in patients on long-term therapy: a double-blind, placebo-controlled trial. Aliment Pharmacol Ther 2006;24:945-54.

30. Laheij RJ, Sturkenboom MC, Hassing RJ, et al. Risk of community-acquired pneumonia and use of gastric acid-suppressive drugs. JAMA 2004;292:1955-60.

31. Dial S, Delaney JA, Barkun AN, et al. Use of gastric acid-suppressive agents and the risk of community-acquired Clostridium difficile-associated disease. JAMA 2005;294:2989-95.

32. Torgerson DJ, Bell-Syer SE. Hormone replacement therapy and prevention of nonvertebral fractures: a meta-analysis of randomized trials. JAMA 2001;285:2891-7.

33. Cranney A, Waldegger L, Zytaruk N, et al. Risedronate for the prevention and treatment of postmenopausal osteoporosis. Cochrane Database Syst Rev 2003;(4):CD004523.

34. Shea B, Wells G, Cranney A, et al. Calcium supplementation on bone loss in postmenopausal women. Cochrane Database Syst Rev 2004;(1):CD004526.

Correspondence to: Dr. William D. Leslie, C5121 St. Boniface

Hospital, 409 Taché Ave., Winnipeg MB R2H 2A6;

bleslie@sbgh.mb.ca 